\title{
Alcohol consumption, body mass index and breast cancer risk by hormone receptor status: Women' Lifestyle and Health Study
}

Aesun Shin ${ }^{1}$, Sven Sandin ${ }^{2}$, Marie Lof ${ }^{3}$, Karen L. Margolis ${ }^{4}$, Kyeezu Kim ${ }^{1}$, Elisabeth Couto ${ }^{2,5}$, Hans Olov Adami ${ }^{2,6}$ and Elisabete Weiderpass $2,7,8,9^{*}$

\begin{abstract}
Background: We aimed to estimate the effect of alcohol consumption on breast cancer risk and to test whether overweight and obesity modifies this association.

Methods: We included in the analysis 45,233 women enrolled in the Swedish Women's Lifestyle and Health study between 1991 and 1992. Participants were followed for occurrence of breast cancer and death until December 2009. Poisson regression models were used, and analyses were done for overall breast cancer and for estrogen receptor positive or negative (ER+, ER-) and progesterone receptor positive and negative (PR+, PR-) tumors separately.

Results: A total of 1,385 breast cancer cases were ascertained during the follow-up period. Overall, we found no statistically significant association between alcohol intake and breast cancer risk after adjustment for confounding, with an estimated relative risk (RR) of 1.01 (95\% Cl: 0.98-1.04) for an increment in alcohol consumption of $5 \mathrm{~g} /$ day. A statistically significant elevated breast cancer risk associated with higher alcohol consumption was found only among women with BMI $\leq 25$ (RR 1.03, $95 \% \mathrm{Cl} 1.0-1.05$ per $5 \mathrm{~g} /$ day increase).

Conclusion: An increase in breast cancer risk with higher alcohol consumption was found for breast cancers in women with a $\mathrm{BMl} \leq 25 \mathrm{~kg} / \mathrm{m}^{2}$.
\end{abstract}

Keywords: Breast cancer, Alcohol, Body mass index, Hormone receptor

\section{Background}

The International Agency for Research on Cancer (IARC) has classified alcohol as a human carcinogen [1] which increases risk of breast cancer both before and after menopause [2]. Alcohol consumption has been estimated to account for $5 \%$ of breast cancer incidence in the European Prospective Investigation into Cancer and Nutrition (EPIC) study [3]. Population attributable fraction of alcohol on breast cancer mortality has been estimated to be $6.4 \%$ in the United Kingdom,[4] $9.4 \%$ in France,[5] and $6 \%$ in the United States [6].

\footnotetext{
* Correspondence: elisabete.weiderpass.vainio@ki.se

${ }^{2}$ Department of Medical Epidemiology and Biostatistics, Karolinska Institutet, PO Box 28117177 Stockholm, Sweden

${ }^{7}$ Department of Research, Cancer Registry of Norway, Institute of

Population-Based Cancer Research, Oslo, Norway

Full list of author information is available at the end of the article
}

Several mechanisms have been proposed to explain this association [2] increasing the probability that alcohol might play a causal role in breast cancer etiology. According to one theory, alcohol increases circulating estrogen levels through interaction with estrogen metabolism [7]. The same mechanism, augmented by decreased levels of sex hormone binding globulin (SHBG) leading to more available estrogen, is also proposed to explain why obesity increases risk of postmenopausal breast cancer [8]. Before menopause, obese women experience a lower risk for breast cancer than lean women; however, the opposite is observed after menopause [2,9]. The inverse association between obesity and risk of premenopausal breast cancer is less well understood mechanistically.

We hypothesized that if alcohol and obesity compete via a similar mechanism to increase risk of postmenopausal breast cancer, then these two exposures may not 
be additive. We further hypothesized that the possible association between these exposures and breast cancer may pertain chiefly or exclusively to hormone receptor positive cancers. We tested our hypotheses in a large prospective study in Sweden.

\section{Methods \\ Study population}

The study cohort comprised participants of the Swedish Women's Lifestyle and Health (WLH) study (http:// ki.se/en/meb/womens-lifestyle-and-health). Details of the study design have been described elsewhere [10, 11]. The study enrolled women age 30-49 who resided in the Uppsala Health Care Region. Among 49,259 women who answered the baseline questionnaire in 1991 and 1992 we excluded 374 for the following reasons: death $(n$ $=68)$, emigration without re-immigration $(n=67)$, previous breast cancer diagnosis $(n=273)$, and uninterpretable answers to questionnaire $(n=2)$. We further excluded 3,652 women with any missing value on selected key covariates (age, birth year, weight, height, education, family history of breast cancer, alcohol consumption, smoking habit, age at menarche, menopausal status, age at menopause, parity, age at the first birth, breast feeding duration, and oral contraceptive use). The final analytic cohort consisted of 45,233 women. Participants were asked to report the number of glasses of beer, wine, and spirits that she currently drank per week, per month, or per year on the baseline questionnaire. On the follow-up questionnaire, consumption frequency and the amount of consumption on one occasion for low alcohol beer, beer, white wine, red wine, dessert wine, and spirits were asked. Body mass index was calculated by using the present height and weight reported on the baseline questionnaire.

Complete follow-up was achieved through linkage to the nationwide health registries in Sweden using the unique national registration number assigned to each individual. Overall breast cancer incidence was obtained from the national register, and estrogen receptor (ER) and progesterone receptor (PR) status of breast tumor was obtained from the regional register. Incident invasive breast cancer (ICD7 170) was ascertained from the Swedish cancer register from 1st September 1992 when the regional breast cancer register in Uppsala was set up, up to 31st December 2009. The Swedish Data Inspection Board and the regional Ethical Committee, Uppsala University, Uppsala, Sweden and the Ethical Committee of the Karolinska Institutet in Stockholm, Sweden approved the study protocol. All participants signed an informed consent form.

\section{Statistical analysis}

We analyzed breast cancer risk associated with alcohol consumption using Poisson regression. This was done with alcohol intake modeled without any predefined shape, with step-function using alcohol categories and also as linear continuous form. To evaluate the functional form between alcohol intake and breast cancer incidence, we estimated the relative risk (RR) using splines, i.e. $\log$ (cancer rate) $=\mathrm{h}$ (alcohol, gram/day) where $\mathrm{h}()$ is an arbitrarily shaped curve. We fitted all models adjusting for age and for other possible confounding variables. Poisson regression is commonly used in survival analysis and gives approximately the same parameter estimates and likelihood ratios as Cox proportional hazards regression when the length of follow-up is split into finer intervals (here we used 2 year intervals) $[12,13]$.

The details for the calculation of total alcohol intake have been described previously [14]. Briefly, the reported quantities of beer, wine, and spirits were converted to grams of alcohol using food composition data from the Swedish National Food Administration [14]. Total alcohol intake was categorized according to the distribution of the variable in the WLH population as categories (0, 0.1-5.0, 5.1-15, and $>15 \mathrm{~g} /$ day), and as a continuous variable. The category of $0-5 \mathrm{~g}$ of alcohol per day corresponds to approximately 0 to 2 glasses of wine per week $(1$ glass $=1 \mathrm{dl}$; alcohol by volume $=10 \%)$. Age was included as a categorical covariate.

We assessed the following potential confounding covariates: educational attainment ( $0-11$ years, $>11$ years), history of breast cancer in mother and/or sister(s) (Yes/No), smoking habits (current, former, never smokers), physical activity at enrollment with five grade scale, age at menarche (years), menopausal status (Yes/No), time varying parity at baseline $(0,1,2,3$, and $>3)$, age at the first child birth (years), breast feeding duration (month), and oral contraceptive use (current/former/never). Age at the first birth was modeled using, for nulliparous women, zero and for parous women extracting the average age at the first birth from the age at the first birth. Self-reported BMI was categorized into two groups $\left(<=25 \mathrm{~kg} / \mathrm{m}^{2}\right.$ and $>25 \mathrm{~kg} /$ $\mathrm{m}^{2}$ ). Age at menopause and the use of hormone replacement therapy (HRT) were both analyzed as time varying variables using the combined 1991 and 2003 follow-up data. Thus, women's menopausal status and HRT use could change along the follow-up period. Participants were censored when death or immigration occurred after entry into the cohort, or at 31st December 2009, whichever came first. The RR of breast cancer comparing different groups of exposure and change in RR by level of modifying covariates was estimated together with associated two-sided $95 \%$ confidence intervals.

We fitted models, for breast cancer overall as well as by ER/PR receptor status, and included parameters for the main effects and the interaction term between BMI $(<=25 \mathrm{~kg} / \mathrm{m} 2$ and $>25 \mathrm{~kg} / \mathrm{m} 2)$ and alcohol intake $(0,0-5$, 5-15 and $>15 \mathrm{~g} /$ day). We calculated RR for breast cancer 
comparing each combination of alcohol and BMI versus low BMI and an alcohol intake of $0 \mathrm{~g} /$ day. In the same model we tested the statistical hypothesis of no interaction using a likelihood ratio test.

All statistical tests were two-sided with $\alpha=0.05$. All models for overall breast cancer were repeated for ER+/PR+, ER+/PR-, and ER-/PR- breast cancers separately. We did not separately analyze the ER-/PR+ tumors owing to the small number.

\section{Results}

Baseline characteristics of study participants are presented in Table 1. High alcohol intake was more common among women with high educational attainment, women who were former or current smokers, women with few children, and among those who had ever used oral contraceptives. The proportion of women with BMI $>25 \mathrm{~kg} / \mathrm{m}^{2}$ was highest among non-drinking women. In addition, the alcohol intake was higher among women with BMI $\leq 25 \mathrm{~kg} / \mathrm{m}^{2}$ (median $=2.6 \mathrm{~g} /$ day for BMI $\leq 25 \mathrm{~kg} / \mathrm{m}^{2}$, median $=1.8 \mathrm{~g} /$ day for BMI $>25 \mathrm{~kg} / \mathrm{m}^{2}$ ). During the follow-up period, a total of 1,385 breast cancer cases were ascertained. Among them, 718 tumors were $\mathrm{ER}+/$ and $\mathrm{PR}+$, 196 were ER+/PR-, 187 were ER -/PR- and 37 were ER-/PR+. Table 2 shows breast cancer risk by alcohol intake in the entire cohort as well as for different hormone receptor subtypes. Alcohol intake was not statistically significantly associated with breast cancer risk, either overall or in different hormone receptor subtypes. We did not find evidence of a non-linear relation between alcohol intake and breast cancer incidence and RR estimated by splines (data not shown).
Overall breast cancer risk increased with increasing alcohol intake among women with BMI $\leq 25 \mathrm{~kg} / \mathrm{m}^{2}(R R=1.03$, 95 \% CI: $1.00-1.05$ per 5 g/day increase), but not among women with BMI over $25 \mathrm{~kg} / \mathrm{m}^{2}$. Similar patterns were observed for all subtypes of breast cancer, but statistical tests for interaction were significant only for ER-/PR- breast cancer $(p=0.04)$ (Table 3).

Additional analysis with menopausal status as timevarying variable or HRT use as time-varying variable did not change the results (data not shown).

\section{Discussion}

After multivariable adjustment we did not observe a statistically significant risk of breast cancer in the combined group of lean and overweight women. However, we found that high intake of alcohol was associated with an increase in overall breast cancer risk only among women with $B M I \leq 25 \mathrm{~kg} / \mathrm{m}^{2}$. It suggests that alcohol and obesity may not act as an additive manner on the breast cancer risk among pre-menopausal women. We also observed statistically significant effect modification of alcohol by body mass index on ER-/PR- breast cancer risk.

Three cohort studies reported similar results [15-17]. In both the EPIC study and the epidemiologic follow-up to the first National Health and Nutrition Examination Study (NHANES), the elevated risk by alcohol consumption was most prominent among both pre- and postmenopausal lean women (BMI $<18.5 \mathrm{~kg} / \mathrm{m}^{2}$ in EPIC and $<22.5 \mathrm{~kg} / \mathrm{m}^{2}$ in NHANES). In the California Teachers Study Cohort, normal weight or marginally overweight women $\left(\mathrm{BMI}<27.3 \mathrm{~kg} / \mathrm{m}^{2}\right)$ whose alcohol consumption level was $\geq 20 \mathrm{~g} /$ day showed $40 \%$ higher risk for breast

Table 1 Baseline characteristics of the Swedish Women's Lifestyle and Health study participants according to alcohol intake

\begin{tabular}{|c|c|c|c|c|}
\hline & \multicolumn{4}{|c|}{ Alcohol intake (g/day) } \\
\hline & 0 & $0.1-5$ & $5.1-15$ & $>15$ \\
\hline No. of participans & 10,153 & 22,249 & 11,734 & 1,097 \\
\hline Age at enrollment (mean) & 39.8 & 39.7 & 40.5 & 41.4 \\
\hline Educational attainment >11 years, (\%) & 46.3 & 56.3 & 61.4 & 61.7 \\
\hline History of breast cancer in mother and/or sister (\%) & 4.2 & 4.2 & 5.3 & 5.9 \\
\hline \multicolumn{5}{|l|}{ Smoking habits (\%) } \\
\hline Never & 50.5 & 43.0 & 32.0 & 18.1 \\
\hline Former & 28.2 & 35.3 & 40.7 & 40.7 \\
\hline Current & 21.3 & 21.7 & 27.3 & 41.2 \\
\hline Age at menarche (mean) & 12.9 & 13.0 & 13.0 & 13.1 \\
\hline Women with more than 3 children (\%) & 32.5 & 27.2 & 24.0 & 23.4 \\
\hline Age at first child birth among parous women (mean) & 23.5 & 24.0 & 24.1 & 23.8 \\
\hline Total duration of breast feeding (months) & 30.9 & 30.8 & 30.2 & 30.3 \\
\hline Ever oral contraceptive use (\%) & 75.1 & 85.0 & 88.2 & 89.7 \\
\hline Post-menopause (\%) & 4.4 & 3.8 & 4.3 & 3.7 \\
\hline Body mass index $\left(>25 \mathrm{~kg} / \mathrm{m}^{2}, \%\right)$ & 31.9 & 24.1 & 21.1 & 24.6 \\
\hline
\end{tabular}


Table 2 Alcohol intake and risk of breast cancer by hormone receptor status in the Swedish Women's Lifestyle and Health study

\begin{tabular}{|c|c|c|c|c|c|c|}
\hline Alcohol intake (g/day) & Total & 0 & $0.1-5$ & $5.1-15$ & $>15$ & Per $5 \mathrm{~g} /$ day increase \\
\hline No. of participants & 45,233 & 10,153 & 22,249 & 11,734 & 1,097 & \\
\hline Person-year & 758,430 & 151,813 & 354,589 & 221,531 & 30,497 & \\
\hline Total breast cancer (No.) & 1,385 & 276 & 646 & 421 & 42 & \\
\hline RR (95 \% Cl)- unadjusted & & 1.0 & $1.07(0.92-1.25)$ & $1.24(1.06-1.45)$ & $1.29(0.99-1.67)$ & $1.02(1.00-1.04)$ \\
\hline RR (95\% Cl)- adjusted & & 1.0 & $1.03(0.89-1.20)$ & $1.16(0.99-1.36)$ & $1.17(0.90-1.53)$ & $1.01(0.98-1.04)$ \\
\hline $\mathrm{ER}(+) / \mathrm{PR}(+)$ breast cancer (No.) & 718 & 140 & 353 & 205 & 19 & \\
\hline RR (95 \% Cl)- unadjusted & & 1.0 & $1.17(0.95-1.46)$ & $1.25(1.00-1.56)$ & $1.21(0.83-1.77)$ & $1.02(0.98-1.05)$ \\
\hline RR (95\% Cl)- adjusted & & 1.0 & $1.13(0.91-1.40)$ & $1.17(0.93-1.47)$ & $1.11(0.76-1.63)$ & $1.01(0.97-1.05)$ \\
\hline ER(+)/PR(-) breast cancer (No.) & 196 & 39 & 88 & 65 & 4 & \\
\hline RR (95 \% Cl)- unadjusted & & 1.0 & $0.99(0.66-1.50)$ & $1.31(0.87-1.99)$ & $1.04(0.51-2.15)$ & $1.01(0.95-1.08)$ \\
\hline RR (95\% Cl)- adjusted & & 1.0 & $1.00(0.66-1.51)$ & $1.35(0.89-2.06)$ & $1.09(0.53-2.25)$ & $1.02(0.95-1.08)$ \\
\hline ER(-)/PR(-) breast cancer (No.) & 187 & 45 & 83 & 51 & 8 & \\
\hline RR (95\% Cl)- unadjusted & & 1.0 & $0.95(0.64-1.42)$ & $1.03(0.67-1.57)$ & $1.27(0.64-2.52)$ & $1.01(0.92-1.10)$ \\
\hline RR (95\% Cl)- adjusted & & 1.0 & $0.90(0.60-1.33)$ & $0.91(0.59-1.39)$ & $1.04(0.52-2.08)$ & $0.98(0.87-1.33)$ \\
\hline
\end{tabular}

Adjusted models were adjusted for educational attainment (0-11 years/>11 years), history of breast cancer in mother and/or sister (Yes/No), smoking habits (current/former/never smokers), age at menarche (years), parity at baseline $(0,1,2,3$, and $>3$ ), age at the first child birth (years), total breast feeding duration (months), and oral contraceptive use (current/former/never)

$R R$ relative risk, $C l$ confidence interval, $E R$ estrogen receptor, $P R$ progesterone receptor

cancer compared with nondrinking normal weight or marginally overweight women (95\% CI 1.10-1.80) [15]. The RR for nondrinking obese women was 1.21 (95\% CI $0.96-1.53)$, and that for obese women with $\geq 20$ g/day alcohol consumption was 1.33 (95\% CI 0.87-2.04). Several case-control studies also suggested effect modification by body mass index, with the effect of moderate alcohol consumption limited to women with low or normal BMI $[18,19]$. In a pooled-analysis, however, no significant effect modification by body mass index on the association between alcohol consumption and breast cancer risk was found [20,21].

Alcohol and obesity probably share common biological mechanisms in breast carcinogenesis through circulating sex hormone levels. Both alcohol consumption and obesity measures (BMI and waist-hip ratio) were associated with circulating hormones, especially SHBG in a cross-sectional study [22]. The variation in SHBG was, however, larger by BMI groups $(54.1 \mathrm{nmol} / \mathrm{L}$ for $<20 \mathrm{~kg}$ / $\mathrm{m}^{2}$ vs. $31.7 \mathrm{nmol} / \mathrm{L}$ for $>27.5 \mathrm{~kg} / \mathrm{m}^{2}$ ) than by alcohol consumption level $(51.1 \mathrm{nmol} / \mathrm{L}$ for non-drinker vs. $43.7 \mathrm{nmol} / \mathrm{L}$ for $\geq 16 \mathrm{~g} /$ day). We postulate that obese women whose SHBG level is already decreased may be less affected by alcohol intake.

Previous epidemiological studies reported associations between alcohol consumption and ER+ breast tumors, whereas weak or null associations were observed for ERtumors [23]. The strongest association was observed for ER+/PR-tumors [23]. While the results were not statistically significant, the pattern of the point estimates in our study is similar to the previous meta-analysis. The mechanisms of stronger association between alcohol consumption and ER+/PR- tumors than $\mathrm{ER}+/ \mathrm{PR}+$ are unknown. Although limited by low statistical power in the stratified analysis by hormonal receptor status, elevated breast cancer risk with higher alcohol consumption was observed for low BMI groups regardless of hormone receptor status of the tumor in our study. In addition, elevated risk with higher alcohol consumption among low BMI group and the highest relative risk among obese non-drinkers for ER-/PR- breast cancer suggested a potential interaction between alcohol intake and ER-/PR- tumors by BMI. This finding should be investigated further in other epidemiological studies. Ovarian hormones are essential for development of both hormone-dependent and hormone-independent breast tumors [24]. Controlled feeding studies suggest that alcohol intake increases circulating estrogen levels in both premenopausal [25-27] and postmenopausal women [28-31]. In contrast, moderate alcohol consumption is also linked to lower progesterone concentration in premenopausal women [26]. Proposed mechanisms of by which alcohol intake effects estrogen levels include an increased rate of aromatization of testosterone or a decreased rate of oxidation of estradiol to estrone [32]. However, only a few studies have reported alcohol consumption, body mass index and endogenous female hormone concentrations simultaneously in postmenopausal women [20,33]. In our analysis, additional adjustment for exogenous hormone use did not change the association between alcohol consumption and breast cancer risk. Further study with comprehensive assessment of hormone 
Table 3 Relative risks (RR) and their $95 \%$ confidence intervals (Cl) on the association between alcohol intake and breast cancer risk by body mass index (BMI) in the Swedish Women's Lifestyle and Health study

\begin{tabular}{|c|c|c|c|c|c|}
\hline & & $<=25 \mathrm{~kg} / \mathrm{m}^{2}$ & & & $\begin{array}{l}\text { BMl } \\
>25 \mathrm{~kg} / \mathrm{m}^{2}\end{array}$ \\
\hline Alcohol intake (g/day) & No. of cases & RR $(95 \% \mathrm{Cl})$ & No. of cases & $\mathrm{RR}(95 \% \mathrm{Cl})$ & p-interaction \\
\hline \multicolumn{6}{|c|}{ Total breast cancer $(n=1,385)$} \\
\hline 0 & 150 & 1.0 & 86 & $0.99(0.76-1.29)$ & \multirow[t]{5}{*}{0.59} \\
\hline $0.1-5$ & 418 & $1.05(0.87-1.26)$ & 181 & $1.00(0.80-1.24)$ & \\
\hline $5.1-15$ & 339 & $1.19(0.98-1.44)$ & 135 & $1.08(0.86-1.37)$ & \\
\hline$>15$ & 56 & $1.32(0.97-1.81)$ & 20 & $0.88(0.55-1.41)$ & \\
\hline Per 5 g/day increase & & $1.03(1.00-1.05)$ & & $0.96(0.88-1.04)$ & \\
\hline \multicolumn{6}{|c|}{$\mathrm{ER}(+) / \mathrm{PR}(+)$ breast cancer $(n=718)$} \\
\hline 0 & 71 & 1.0 & 46 & $1.08(0.75-1.57)$ & \multirow[t]{5}{*}{0.69} \\
\hline $0.1-5$ & 217 & $1.14(0.87-1.49)$ & 109 & $1.23(0.91-1.66)$ & \\
\hline $5.1-15$ & 167 & $1.22(0.92-1.61)$ & 72 & $1.18(0.85-1.65)$ & \\
\hline$>15$ & 26 & $1.28(0.81-2.03)$ & 10 & $0.90(0.46-1.76)$ & \\
\hline Per 5 g/day increase & & $1.03(0.99-1.06)$ & & $0.93(0.83-1.05)$ & \\
\hline \multicolumn{6}{|c|}{$\mathrm{ER}(+) / \mathrm{PR}(-)$ breast cancer $(n=196)$} \\
\hline 0 & 23 & 1.0 & 10 & $0.69(0.33-1.45)$ & \multirow[t]{5}{*}{0.98} \\
\hline $0.1-5$ & 55 & $0.94(0.58-1.53)$ & 23 & $0.77(0.43-1.39)$ & \\
\hline $5.1-15$ & 55 & $1.29(0.79-2.13)$ & 20 & $0.98(0.53-1.81)$ & \\
\hline$>15$ & 7 & $1.06(0.45-2.50)$ & 3 & $0.80(0.24-2.69)$ & \\
\hline Per 5 g/day increase & & $1.02(0.96-1.09)$ & & $0.98(0.82-1.18)$ & \\
\hline \multicolumn{6}{|c|}{ ER(-)/PR(-) breast cancer $(n=187)$} \\
\hline 0 & 17 & 1.0 & 19 & $1.95(1.01-3.76)$ & \multirow[t]{5}{*}{0.04} \\
\hline $0.1-5$ & 60 & $1.29(0.75-2.22)$ & 21 & $1.01(0.53-1.93)$ & \\
\hline $5.1-15$ & 44 & $1.31(0.74-2.30)$ & 15 & $1.03(0.51-2.08)$ & \\
\hline$>15$ & 10 & $1.96(0.89-4.34)$ & 1 & $0.36(0.05-2.74)$ & \\
\hline Per $5 \mathrm{~g} /$ day increase & & $1.02(0.94-1.11)$ & & $0.80(0.59-1.09)$ & \\
\hline
\end{tabular}

Adjusted models were adjusted for educational attainment (0-11 years/>11 years), history of breast cancer in mother and/or sister (Yes/No), smoking habits (current/former/never smokers), age at menarche (years), parity at baseline $(0,1,2,3$, and $>3$ ), age at the first child birth (years), total breast feeding duration (months), and oral contraceptive use (current/former/never)

$E R$ estrogen receptor, $P R$ progesterone receptor

levels and adiposity measures would help to explain the mechanisms of the excess risk of alcohol consumption in lean premenopausal women.

Strengths of our study include its prospective design, which minimizes potential for recall bias. Potential confounders of the association between alcohol consumption and breast cancer risk, such as family history of breast cancer, were adjusted for in the multivariate model. Breast cancer ascertainment by linkage to the registries ensures virtually complete follow-up. In addition, information on hormone receptor status was available for most of breast cancer patients with relatively high completeness. Another strength is the age structure of the cohort, since few cohort studies aimed to include predominantly premenopausal women [14].

Limitation of the study includes that information on alcohol consumption was assessed at baseline and follow- up surveys and may not accurately reflect long- term consumption habit. Analysis by hormone receptor status may lack statistical power due to small numbers of cases in each exposure groups.

\section{Conclusions}

In conclusion, an increase in breast cancer risk with higher alcohol consumption was found for all breast cancers only among women with a BMI $\leq 25 \mathrm{~kg} / \mathrm{m}^{2}$. The competing effects of obesity and alcohol consumption on circulating sex hormone levels may explain the results.

\section{Abbreviations}

BMI: body mass index; EPIC: European Prospective Investigation into Cancer and Nutrition; ER: estrogen receptor; HRT: hormone replacement therapy; IARC: the International Agency for Research on Cancer; NHANES: National Health and Nutrition Examination Study; PR: progesterone receptor; RR: relative risk; SHBG: sex hormone binding globulin; WLH: Women's Lifestyle and Health. 


\section{Competing interest}

The authors declare that they have no competing interests.

\section{Authors' contributions}

AS and EW conceived of the study. KZK performed the literature search and review. SS conducted the statistical analysis. AS, EW and SS wrote the manuscript. ML, KLM, EC, HOA involved in revising the manuscript critically for important intellectual content. All authors read and approved the final version of manuscript.

\section{Acknowledgements}

This work was supported by the Basic Science Research Program of the National Research Foundation of Korea (NRF-2013R1A1A2A10008260) to Aesun Shin and Distinguished Professor Award to Hans-Olov Adami (grant number Dnr: 2368/10-221).

\section{Author details}

${ }^{1}$ Department of Preventive Medicine, Seoul National University College of Medicine, Seoul, South Korea. ${ }^{2}$ Department of Medical Epidemiology and Biostatistics, Karolinska Institutet, PO Box 28117177 Stockholm, Sweden. ${ }^{3}$ Department of Biosciences and Nutrition, Karolinska Institutet, Stockholm, Sweden. ${ }^{4}$ HealthPartners Institute for Education and Research, Minneapolis, USA. ${ }^{5}$ Norwegian Knowledge Centre for the Health Services, Health Economic and Drug Unit, Oslo, Norway. ${ }^{6}$ Department of Epidemiology, Harvard School of Public Health, Boston, USA. ${ }^{7}$ Department of Research, Cancer Registry of Norway, Institute of Population-Based Cancer Research, Oslo, Norway. ${ }^{8}$ Department of Community Medicine, Faculty of Health Sciences, University of Tromsø, The Arctic University of Norway, Troms $\varnothing$, Norway. ${ }^{9}$ Genetic Epidemiology Group, Folkhälsan Research Center, Helsinki, Finland.

Received: 12 August 2014 Accepted: 3 November 2015

Published online: 09 November 2015

\section{References}

1. Secretan B, Straif K, Baan R, Grosse Y, El Ghissassi F, Bouvard V, et al. A review of human carcinogens-Part E: tobacco, areca nut, alcohol, coal smoke, and salted fish. Lancet Oncol. 2009;10(11):1033-4.

2. World Cancer Research Fund/American Institute for Cancer Research. Food, nutrition, physical activity, and the prevention of cancer: a global perspective. Washington DC: AICR; 2007.

3. Schutze M, Boeing H, Pischon T, Rehm J, Kehoe T, Gmel G, et al. Alcohol attributable burden of incidence of cancer in eight European countries based on results from prospective cohort study. BMJ. 2011;342:d1584.

4. Parkin DM. 3. Cancers attributable to consumption of alcohol in the UK in 2010. Br J Cancer. 2011;105 Suppl 2:S14-8.

5. Boffetta P, Tubiana M, Hill C, Boniol M, Aurengo A, Masse R, et al. The causes of cancer in France. Ann Oncol. 2009;20(3):550-5.

6. Key J, Hodgson S, Omar RZ, Jensen TK, Thompson SG, Boobis AR, et al. Meta-analysis of studies of alcohol and breast cancer with consideration of the methodological issues. Cancer Causes Control. 2006;17(6):759-70.

7. Hong J, Holcomb VB, Dang F, Porampornpilas K, Nunez NP. Alcohol consumption, obesity, estrogen treatment and breast cancer. Anticancer Res. 2010;30(1):1-8.

8. Key TJ, Appleby PN, Reeves GK, Roddam AW, Helzlsouer KJ, Alberg AJ, et al. Circulating sex hormones and breast cancer risk factors in postmenopausal women: reanalysis of 13 studies. Br J Cancer. 2011;105(5):709-22.

9. Wei EK, Wolin KY, Colditz GA. Time course of risk factors in cancer etiology and progression. J Clin Oncol. 2010;28(26):4052-7.

10. Kumle M, Weiderpass E, Braaten T, Persson I, Adami HO, Lund E. Use of oral contraceptives and breast cancer risk: The Norwegian-Swedish Women's Lifestyle and Health Cohort Study. Cancer Epidemiol Biomarkers Prev. 2002;11(11):1375-81.

11. Roswall N, Sandin S, Adami HO, Weiderpass E. Cohort Profile: The Swedish Women's Lifestyle and Health cohort. Int J Epidemiol. 2015.

12. Whitehead J. Fitting Cox's regression model to survival data using GLIM. J Royal Stat Soc Series C. 1980;29:268-75.

13. Pawitan $Y$. In all likelihood: Statistical modeling and inference using likelihood. Oxford: Clarendon Press; 2001.
14. Behrens G, Leitzmann MF, Sandin S, Lof M, Heid IM, Adami HO, et al. The association between alcohol consumption and mortality: the Swedish women's lifestyle and health study. Eur J Epidemiol. 2011;26(2):81-90.

15. Horn-Ross PL, Canchola AJ, West DW, Stewart SL, Bernstein L, Deapen D, et al. Patterns of alcohol consumption and breast cancer risk in the California Teachers Study cohort. Cancer Epidemiol Biomarkers Prev. 2004;13(3):405-11.

16. Schatzkin A, Jones DY, Hoover RN, Taylor PR, Brinton LA, Ziegler RG, et al Alcohol consumption and breast cancer in the epidemiologic follow-up study of the first National Health and Nutrition Examination Survey. N Engl J Med. 1987;316(19):1169-73.

17. Tjonneland A, Christensen J, Olsen A, Stripp C, Thomsen BL, Overvad K, et al. Alcohol intake and breast cancer risk: the European Prospective Investigation into Cancer and Nutrition (EPIC). Cancer Causes Control. 2007;18(4):361-73.

18. Harris RE, Spritz N, Wynder EL. Studies of breast cancer and alcohol consumption. Prev Med. 1988;17(6):676-82.

19. Terry MB, Zhang FF, Kabat G, Britton JA, Teitelbaum SL, Neugut Al, et al. Lifetime alcohol intake and breast cancer risk. Ann Epidemiol. 2006;16(3):230-40.

20. Hamajima N, Hirose K, Tajima K, Rohan T, Calle EE, Heath Jr CW, et al. Alcohol, tobacco and breast cancer-collaborative reanalysis of individual data from 53 epidemiological studies, including 58,515 women with breast cancer and 95,067 women without the disease. Br J Cancer. 2002;87(11):1234-45.

21. Smith-Warner SA, Spiegelman D, Yaun SS, van den Brandt PA, Folsom AR, Goldbohm RA, et al. Alcohol and breast cancer in women: a pooled analysis of cohort studies. JAMA. 1998;279(7):535-40.

22. Verkasalo PK, Thomas HV, Appleby PN, Davey GK, Key TJ. Circulating levels of sex hormones and their relation to risk factors for breast cancer: a crosssectional study in 1092 pre- and postmenopausal women (United Kingdom). Cancer Causes Control. 2001;12(1):47-59.

23. Suzuki R, Orsini N, Mignone L, Saji S, Wolk A. Alcohol intake and risk of breast cancer defined by estrogen and progesterone receptor status-a meta-analysis of epidemiological studies. Int J Cancer. 2008;122(8):1832-41.

24. Nandi S, Guzman RC, Yang J. Hormones and mammary carcinogenesis in mice, rats, and humans: a unifying hypothesis. Proc Natl Acad Sci U S A. 1995;92(9):3650-7.

25. Reichman ME, Judd JT, Longcope C, Schatzkin A, Clevidence BA, Nair PP, et al. Effects of alcohol consumption on plasma and urinary hormone concentrations in premenopausal women. J Natl Cancer Inst. 1993;85(9):722-7.

26. Sarkola T, Makisalo H, Fukunaga T, Eriksson CJ. Acute effect of alcohol on estradiol, estrone, progesterone, prolactin, cortisol, and luteinizing hormone in premenopausal women. Alcohol Clin Exp Res. 1999;23(6):976-82.

27. Mendelson JH, Mello NK. Chronic alcohol effects on anterior pituitary and ovarian hormones in healthy women. J Pharmacol Exp Ther. 1988;245(2):407-12.

28. Ginsburg ES, Mello NK, Mendelson JH, Barbieri RL, Teoh SK, Rothman M, et al. Effects of alcohol ingestion on estrogens in postmenopausal women. JAMA. 1996;276(21):1747-51.

29. Mahabir S, Baer DJ, Johnson LL, Dorgan JF, Campbell W, Brown E, et al. The effects of moderate alcohol supplementation on estrone sulfate and DHEAS in postmenopausal women in a controlled feeding study. Nutr J. 2004;3:11.

30. Purohit V. Moderate alcohol consumption and estrogen levels in postmenopausal women: a review. Alcohol Clin Exp Res. 1998;22(5):994-7.

31. Sierksma A, Sarkola T, Eriksson CJ, van der Gaag MS, Grobbee DE, Hendriks HF. Effect of moderate alcohol consumption on plasma dehydroepiandrosterone sulfate, testosterone, and estradiol levels in middle-aged men and postmenopausal women: a diet-controlled intervention study. Alcohol Clin Exp Res. 2004;28(5):780-5.

32. Gill J. The effects of moderate alcohol consumption on female hormone levels and reproductive function. Alcohol Alcohol. 2000;35(5):417-23.

33. Hvidtfeldt UA, Gunter MJ, Lange T, Chlebowski RT, Lane D, Farhat GN, et al. Quantifying mediating effects of endogenous estrogen and insulin in the relation between obesity, alcohol consumption, and breast cancer. Cancer Epidemiol Biomark Prev. 2012;21(7):1203-12. 